\title{
REVIEWS
}

\section{Cannabidiol for Viral Diseases: Hype or Hope?}

\author{
Alex Mabou Tagne, ${ }^{1}$ Barbara Pacchetti, ${ }^{2}$ Mikael Sodergren, ${ }^{2,3}$ Marco Cosentino, ${ }^{1, *}$ and Franca Marino ${ }^{1}$
}

\begin{abstract}
Background: The possibility of cannabidiol (CBD) to be used as an antiviral or to treat viral diseases has received limited attention so far, despite the growing number of claims that CBD could be used for the treatment of viral infection-related conditions.

Aim and Methods: Therefore, we systematically retrieved and critically evaluated the scientific literature available on PubMed and the claims on the Internet, to assess the current state of knowledge on the use of CBD in viral diseases, and to provide suggestions for future research directions.

Results: PubMed search referenced two original articles supporting the use of CBD for the treatment of hepatitis $\mathrm{C}$ and Kaposi sarcoma and one article reporting the ability of CBD to reduce neuroinflammation in a virusinduced animal model of multiple sclerosis. Internet search found 25 websites claiming more indications for CBD. Remarkably, those claims were provided mostly by commercial websites and were not supported by appropriate scientific references.

Conclusion: Although preclinical studies suggest the potential effectiveness of CBD in viral diseases such as hepatitis $C$ and Kaposi sarcoma, clinical evidence is still lacking. Anecdotal experiences of CBD use retrieved on the Internet, on the other side, lack any support from sound scientific evidence, although they might in some cases provide suggestions for conditions associated with viral infections that may deserve proper assessment in welldesigned clinical trials.
\end{abstract}

Keywords: cannabidiol; cannabinoid; antiviral effects; hepatitis C; herpes; Ebola

\section{Introduction}

Cannabis (Cannabis sativa L., fam. Cannabaceae) and its derivatives are currently credited with treating a variety of medical conditions, including pain in adults, chemotherapy-induced nausea and vomiting, and spasticity associated with multiple sclerosis (MS). ${ }^{1}$ Many medical applications of cannabis and cannabinoids are related to their anti-inflammatory activity, which is, however, a double-edged sword under certain conditions. Particularly in viral infections, the anti-inflammatory activity of $\Delta^{9}$-tetrahydrocannabinol $\left(\Delta^{9}\right.$-THC $),{ }^{2}$ the main component of cannabis, may jeopardize host immune responses to acute viral infections, leading to disease progression and death in the worst case. ${ }^{3,4}$ Nonetheless, $\Delta^{9}$-THC may be beneficial in viral infections where the host inflammatory response is pathogenic, ${ }^{3}$ although its psychoactive and addictive potential is a significant limitation to its therapeutic development.
Cannabidiol (CBD) is one of the main cannabinoids found in the cannabis plant that, unlike $\Delta^{9}$-THC, is devoid of psychotropic effects and addictive potential. ${ }^{5}$ Long neglected, CBD is currently gaining traction as a therapeutic vector for a vast range of pathological conditions. ${ }^{6}$ Recently, Epidiolex ${ }^{\circledR}$, a CBD-only drug, has been approved by Food and Drug Administration (FDA) to treat seizures in children with intractable forms of epilepsy. ${ }^{7}$ Since then, researchers have begun to search for more therapeutic applications for CBD.

Fragmentary evidence points to a possible use of CBD in viral infections. Indeed, several plant-derived compounds do have proven antiviral activity across a broad array of different chemical groups and structures. ${ }^{8,9}$ The main point is that plant secondary metabolites have evolved to become antimicrobial, and this includes many phenol-based compounds, such as those with

${ }^{1}$ Center for Research in Medical Pharmacology, University of Insubria, Varese, Italy.

${ }^{2}$ Emmac Life Sciences, London, United Kingdom.

${ }^{3}$ Department of Surgery and Cancer, Imperial College London, London, United Kingdom.

*Address correspondence to: Marco Cosentino, MD, PhD, Center for Research in Medical Pharmacology, University of Insubria, Via Monte Generoso 71, Varese, 21100, Italy, E-mail: marco.cosentino@uninsubria.it 
terpenoid moieties. ${ }^{10}$ Despite the lack of research specifically on phytocannabinoids, there is a lot of scientific data on terpenoids. ${ }^{9,10}$ There is also a lot on the known targets of CBD, for instance, around its ability to induce apoptosis in mammalian cells. ${ }^{11}$ Apoptosis is well known to be a critical component of host responses to viral infections. ${ }^{12}$ On the basis of this background, we critically reviewed the scientific literature to examine the current state of knowledge on the use of CBD in viral infections, and to provide suggestions for future research directions and perspectives. Since CBD-based products are popular and easily available to the general public, ${ }^{13}$ and the Internet is increasingly used as a source of health-related information, ${ }^{14}$ we also consulted the Internet for anecdotal evidence or claims that CBD is being used or reported as an antiviral or in general as an aid in viral diseases.

\section{Methods}

This systematic review follows the guidelines validated by PRISMA, the Preferred Reporting Items for Systematic Reviews and Meta-analyses.

Systematic review of the scientific literature PubMed was searched to retrieve any relevant studies supporting the antiviral activity of CBD. Searches were conducted in March 2019 without restriction of language or years. Search algorithm was obtained by combining terms related to "cannabidiol" with those related to "viral infections" or "virus" as shown in Table 1. Referen- ces identified through this process were subsequently scanned for selection criteria. Inclusion criteria included studies of the antiviral activity of pure CBD. Excluded topics included review articles, duplicates, and studies of synthetic analogs, enriched extracts, or metabolites of CBD. Thereafter, reference lists of the included articles were screened for additional reports.

\section{Internet search}

During May 2019, we searched DuckDuckGo without restriction of language and years for anecdotal evidence or signals that CBD is being used or reported as antiviral, using the "cannabidiol virus" search string. Thereafter, supporting references retrieved from the included websites were screened for additional records. The choice of DDG as search engine, among others, was dictated by the goal of ensuring the reproducibility of our search results, as strongly recommended elsewhere. ${ }^{15}$ DDG distinguishes itself from other search engines by not profiling its users and by showing all users the same search results for a given search term.

\section{Results}

Systematic review of the scientific literature

Full details of the search strategy are summarized in Figure 1. PubMed referenced 77 articles, only 3 of which were relevant to this review (Table 2). The complete list of articles retrieved along with reasons for exclusion is presented as Supplementary Table S1.

Table 1. Search Algorithm for PubMed Screening

\begin{tabular}{|c|c|}
\hline CBD (https://www.ncbi.nlm.nih.gov/mesh/?term=cannabidiol) & $\begin{array}{l}\text { Virus (https://www.ncbi.nlm.nih.gov/mesh/?term=virus) } \\
\text { Viral infections (https://www.ncbi.nlm.nih.gov/mesh/?term=viral + infections) }\end{array}$ \\
\hline $\begin{array}{l}\text { CBD } \\
\text { Cannabidiol-3-monomethyl ether } \\
\text { 5-(1,1-dimethylheptyl)cannabidiol } \\
\text { Nabiximols } \\
\text { 6"-azidohex-2"-yne-cannabidiol } \\
\text { Cannabidiol (abn-cbd,(-)-4-(3-3,4-trans-p-menthadien- } \\
\quad(1,8) \text {-yl)olivetol) } \\
\text { 4-(3-3,4-p-menthadien-(1,8)-yl)olivetol } \\
\text { Desoxycannabidiol } \\
\text { Cannabidiol hydroxyquinone } \\
\text { Cannabidiol dimethyl ether } \\
\text { HUF-101 }\end{array}$ & $\begin{array}{l}\text { Virus diseases } \\
\text { Viral infections } \\
\text { Virus } \\
\text { Viruses } \\
\text { Influenza A virus } \\
\text { HSV } \\
\text { Respiratory syncytial virus } \\
\text { Epstein-Barr virus } \\
\text { Hepatitis A virus } \\
\text { HBV } \\
\text { HCV } \\
\text { Influenza B virus } \\
\text { Influenza A virus } \\
\text { Dengue virus } \\
\text { Zika virus } \\
\text { Ebola virus } \\
\text { Encephalomyelitis } \\
\text { Chikungunya virus } \\
\text { HIV }\end{array}$ \\
\hline
\end{tabular}




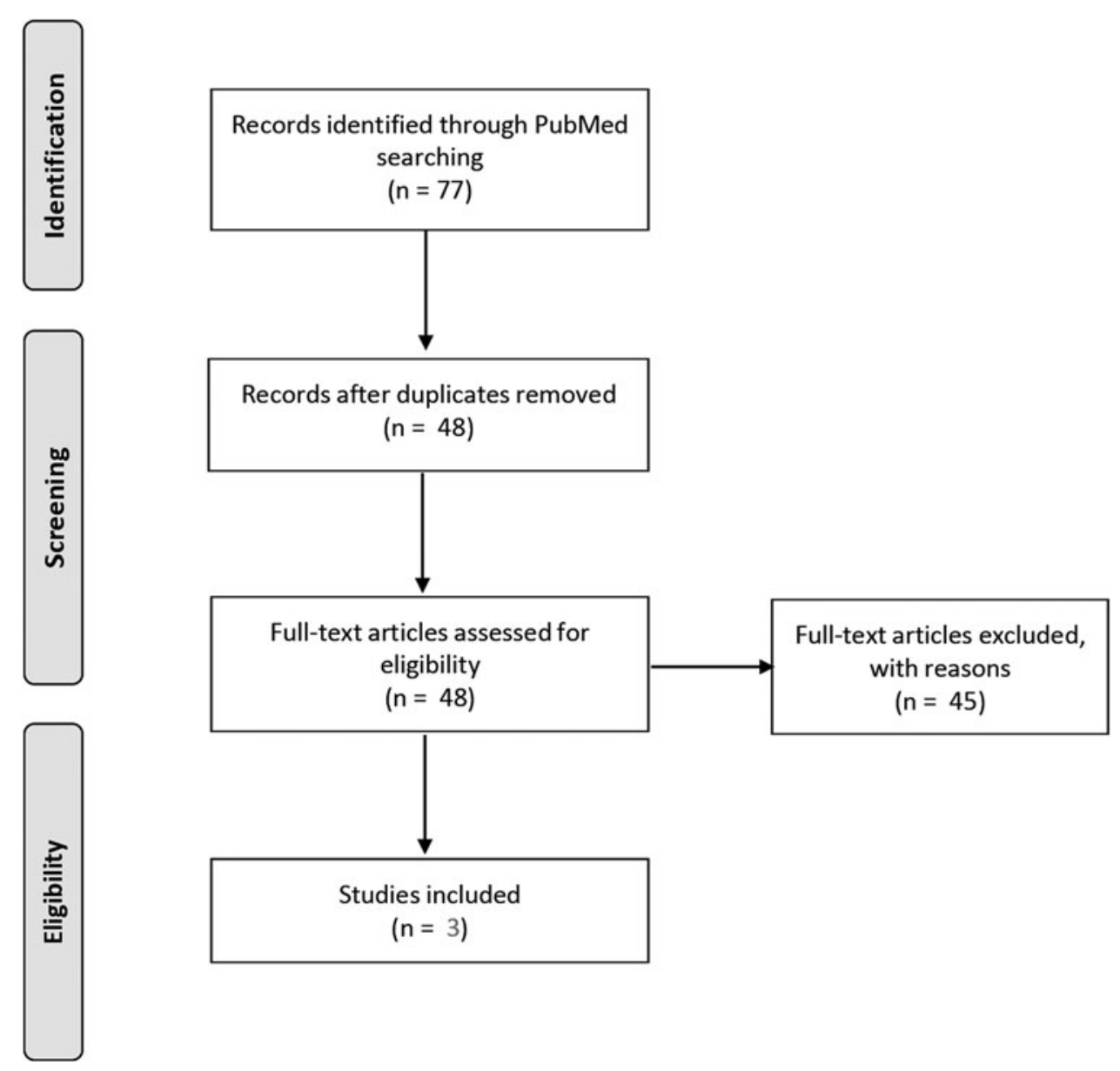

FIG. 1. Strategy for PubMed search.

The most recent article reports an in vitro study suggesting a direct antiviral effect of $\mathrm{CBD}$ against hepatitis $\mathrm{C}$ virus (HCV), but not against hepatitis $B$ virus (HBV). ${ }^{16}$ Researchers cultured HepG2 2.2.15 or Huh7.5 cell lines to generate $\mathrm{HBV}$ and $\mathrm{HCV}$, respectively. After days of culture in the presence of up to $10 \mu \mathrm{M}$ CBD, CBD concentration-dependently inhibited HCV replication by up to $86.4 \%\left(\mathrm{EC}_{50}=3.163 \mu \mathrm{M}\right)$. The HCV inhibitory effect of CBD at $10 \mu \mathrm{M}$ was comparable to that of interferon alpha (IFN- $\alpha) 10 \mathrm{IU} / \mathrm{mL}$, used as a positive control. Remarkably, CBD $10 \mu \mathrm{M}$ was less cytotoxic than IFN- $\alpha$ $10 \mathrm{IU} / \mathrm{mL}$. On the other hand, comparison with sofosbuvir using the same experimental model showed less efficacy and more cytotoxicity.

The other study shows an indirect antiviral action of CBD against Kaposi's sarcoma-associated herpesvirus (KSHV) using a model of KSHV-infected human dermal microvascular endothelial cells (HMVECs). ${ }^{17}$
HMVECs were pretreated with various concentrations of CBD, followed by infection with KSHV. After $48 \mathrm{~h}$ of culture, results showed that CBD up to $10 \mu \mathrm{M}$ did not affect the efficiency with which KSHV infected HMVECs, but it reduced KSHV-infected cells proliferation $\left(\mathrm{IC}_{50}=2.08 \mu \mathrm{M}\right)$ and enhanced apoptosis $\left(\mathrm{EC}_{50}=1.04 \mu \mathrm{M}\right)$. In addition, $\mathrm{CBD}$ treatment was able to prevent the transformation of normal cells into KSHV-associated cancers. The observed effects of CBD occurred through inhibition of the expression of KSHV viral G protein-coupled receptor, chemokine growth-regulated protein $\alpha$, vascular endothelial growth factor receptor 3 , and vascular endothelial growth factor $\mathrm{C}$.

The last article supports the use of CBD to reverse the deleterious effects of neuroinflammation induced by Theiler's murine encephalomyelitis virus (TMEV). ${ }^{18}$ Using the model of TMEV-induced 
Table 2. Summary of the Effects of Cannabidiol in Viral Infections

\begin{tabular}{|c|c|c|c|c|c|}
\hline Experimental model & Methods & Effects & $\begin{array}{l}\text { Positive } \\
\text { controls }\end{array}$ & Mechanism & References \\
\hline \multirow[t]{2}{*}{ HepG2 2.2.15 cells } & $\begin{array}{l}\text { Real-time quantitative } \\
\text { TaqMan PCR assay }\end{array}$ & No effect on HBV replication & Lamivudine & $\mathrm{N} / \mathrm{A}$ & Lowe et al. ${ }^{16}$ \\
\hline & MTS based assay & $\begin{array}{l}\text { Significant cytotoxicity at } \\
10 \mu \mathrm{M} \text { for } 6 \text { days }\end{array}$ & & $\mathrm{N} / \mathrm{A}$ & Lowe et al. ${ }^{16}$ \\
\hline \multirow[t]{2}{*}{ Huh7.5 cells } & $\begin{array}{l}\text { Renilla Luciferase Assay } \\
\text { System }\end{array}$ & $\begin{array}{l}\text { Significant inhibition of } \mathrm{HCV} \\
\text { replication in a } \\
\text { concentration-dependent } \\
\text { manner }\end{array}$ & $\begin{array}{l}\text { IFN- } \alpha \text { and } \\
\text { sofosbuvir }\end{array}$ & $\mathrm{N} / \mathrm{A}$ & Lowe et al. ${ }^{16}$ \\
\hline & CytoTox-1 reagent & $\begin{array}{l}\text { Slight cytotoxicity at } 10 \mu \mathrm{M} \\
\text { for } 72 \mathrm{~h}\end{array}$ & & N/A & Lowe et al. ${ }^{16}$ \\
\hline $\begin{array}{l}\text { KSHV-infected } \\
\text { HMVECs; }\end{array}$ & Fluorescence & $\begin{array}{l}\text { No effect on the modulation } \\
\text { of the infection }\end{array}$ & N/A & $\mathrm{N} / \mathrm{A}$ & Maor et al. ${ }^{17}$ \\
\hline \multirow[t]{3}{*}{$\begin{array}{l}\text { Kaposi sarcoma tissue } \\
\text { samples }\end{array}$} & MTS based assay & $\begin{array}{l}\text { Inhibition of the } \\
\text { proliferation }\end{array}$ & N/A & N/A & Maor et al. ${ }^{17}$ \\
\hline & TUNEL method & Induction of apoptosis & N/A & $\mathrm{N} / \mathrm{A}$ & Maor et al. ${ }^{17}$ \\
\hline & $\begin{array}{l}\text { Immunohistochemistry; } \\
\text { Western blot; } \\
\text { ELISA }\end{array}$ & $\begin{array}{l}\text { Prevention of the } \\
\text { transformation of normal } \\
\text { cells to KSHV-associated } \\
\text { cancers }\end{array}$ & N/A & $\begin{array}{l}\text { Inhibited expression of } \\
\text { vGPCR in cutaneous Kaposi } \\
\text { sarcoma lesions; } \\
\text { Decreased GRO- } \alpha \text { and IL-8; } \\
\text { Decreased VEGF-C, VEGF-D, } \\
\text { and VEGFR-3 }\end{array}$ & Maor et al. ${ }^{17}$ \\
\hline $\begin{array}{l}\text { TMEV-induced } \\
\text { demyelinating disease- } \\
\text { susceptible female } \\
\text { SJL/J mice; } \\
\text { Murine brain } \\
\text { endothelial cells } \\
\text { (b.end5); }\end{array}$ & $\begin{array}{l}\text { Activity cage coupled } \\
\text { to a Digiscan Analyzer }\end{array}$ & $\begin{array}{l}\text { Amelioration of motor } \\
\text { deficits }\end{array}$ & N/A & $\begin{array}{l}\text { Decreased microglial } \\
\text { activation and production of } \\
\text { the proinflammatory } \\
\text { cytokine IL- } 1 \beta \text {; } \\
\text { Decreased TNF } \alpha \text { and IL- } 1 \beta \\
\text { mRNA induction in the spinal } \\
\text { cord }\end{array}$ & Mecha et al. ${ }^{18}$ \\
\hline $\begin{array}{l}\text { Rat astrocytes prepared } \\
\text { from postnatal Wistar } \\
\text { pups; } \\
\text { Nervous tissue } \\
\text { (prefrontal cortex and } \\
\text { spinal cords) or from } \\
\text { cell cultures using } \\
\text { RNeasy mini columns }\end{array}$ & Microscopy & $\begin{array}{l}\text { Decrease of leukocyte } \\
\text { infiltration in the brains }\end{array}$ & $\mathrm{N} / \mathrm{A}$ & $\begin{array}{l}\text { Reduced leukocyte adhesion } \\
\text { to endothelial cells; } \\
\text { Inhibition of VCAM-1 } \\
\text { production; } \\
\text { Reduction of CCL2, CCL5, } \\
\text { and CCR } 2 \text { mRNA induction in } \\
\text { the prefrontal cortex; } \\
\text { Activation of adenosine A2A } \\
\text { receptors }\end{array}$ & Mecha et al. ${ }^{18}$ \\
\hline
\end{tabular}

CCL, C-C chemokine ligand; CCR2, C-C chemokine receptor type 2; ELISA, enzyme-linked immunosorbent assay; GRO- $\alpha$, chemokine growthregulated protein $\alpha$; IFN- $\alpha$, interferon alpha; IL, interleukin; KSHV, Kaposi's sarcoma-associated herpesvirus; mRNA, messenger RNA; MTS, 3-(4,5dimethylthiazol-2-yl)-5-(3-carboxymethoxyphenyl)-2-(4-sulfophenyl)-2H-tetrazolium; N/A, not available; TMEV, Theiler's murine encephalomyelitis virus; TNF $\alpha$, tumor necrosis factor alpha; TUNEL, terminal deoxynucleotidyl transferase dUTP nick end labeling; VCAM-1, vascular cell adhesion protein 1; VEGF, vascular endothelial growth factor; vGPCR, viral G protein-coupled receptor.

demyelination in mice, Mecha et al. ${ }^{18}$ showed that subchronic treatment with CBD $(5 \mathrm{mg} / \mathrm{kg})$ decreased leukocyte infiltration and microglia activation in the brain of TMEV-infected mice, improving motor symptomatology and the neuroinflammation in the chronic phase of infection. Interestingly, when administered for 10 days to mice immediately after infection with TMEV, CBD exerted long-lasting effects on the onset of symptoms, impairing the chronic phase of the disease, restoring motor function and reversing neuroinflammation. The study does not provide any experimental evidence of direct or indirect antiviral effect of CBD. The observed antiinflammatory effects of $\mathrm{CBD}$ involved, at least in part, the activation of adenosine $\mathrm{A} 2 \mathrm{~A}$ receptors.

\section{Internet review}

Full details of the search strategy are summarized in Figure 2. In total, 179 references were identified, 24 of which were deemed potentially relevant to this review based on the screening of their content (Table 3). One reference was added after the screening of supporting references of the included websites. The complete list of the websites retrieved along with reasons for exclusion is provided as Supplementary Table S2. Excluded records were websites linked to the articles already retrieved on PubMed, website pages that did not report claims on antiviral effects of CBD, duplicate references, and nonfunctional website pages.

Most of the selected websites claim benefits of using $\mathrm{CBD}$ for the treatment of several viral diseases, including 

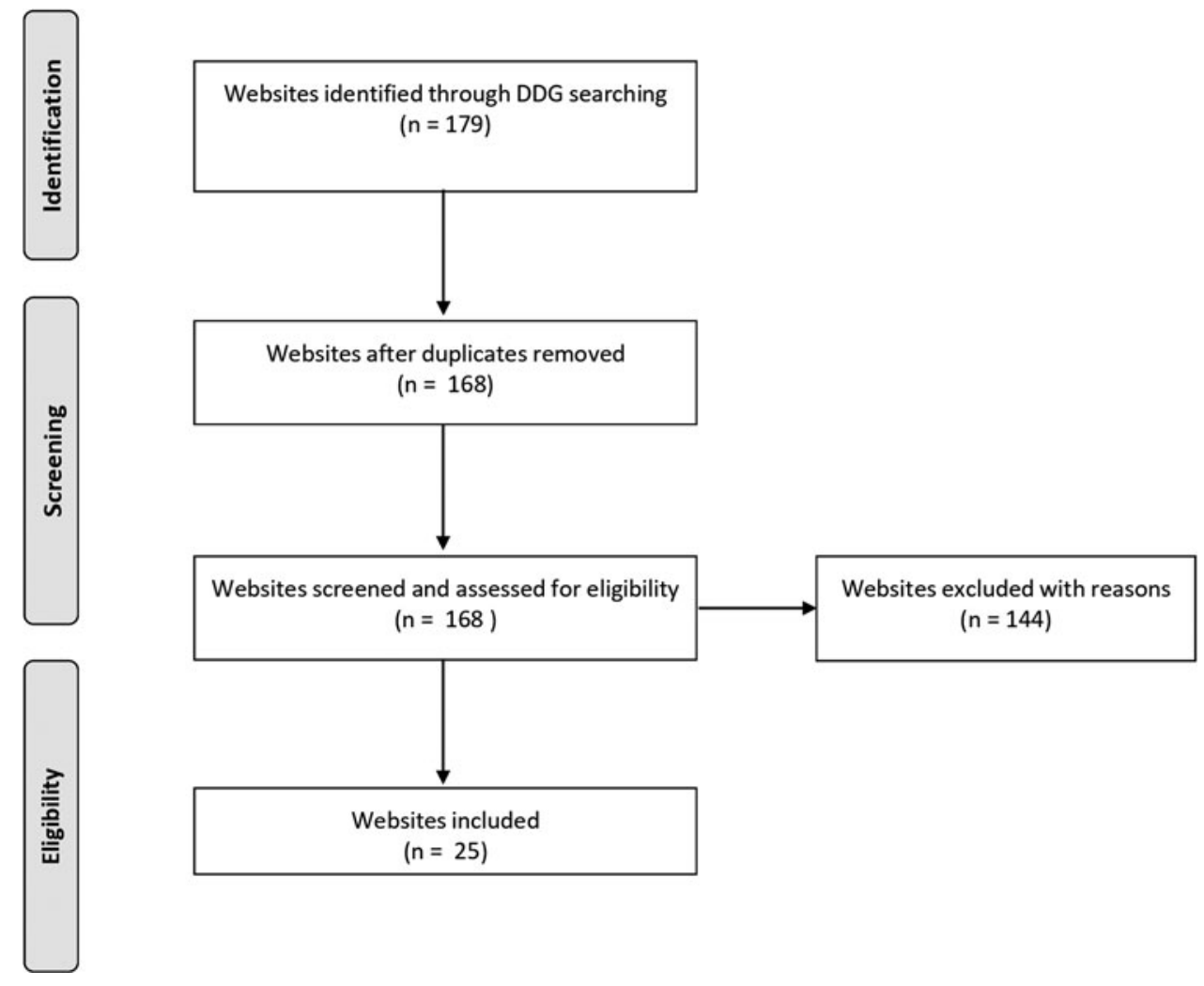

FIG. 2. Strategy for Internet search. DDG, DuckDuckGo.

oral and genital herpes $(n=8)$, shingles $(n=3)$, hepatitis C $(n=3)$, colds and flu $(n=3)$, HIV/AIDS $(n=2)$, Ebola $(n=2)$, and infectious mononucleosis $(n=1)$. Those claims were provided by commercial websites $(n=11)$, education platform $(n=8)$, online media $(n=1)$, and LinkedIn $(n=1)$. In most cases, however, the reported benefits of CBD for viral infections were not supported by appropriate scientific references.

Other references reviewed were blogs $(n=3)$ or discussion forum $(n=1)$, where users could share and compare their views, beliefs, and experiences of CBD use in viral infections. Remarkably, in a discussion forum, ${ }^{*}$ many claims were made about the benefits of $\mathrm{CBD}$ in the treatment of shingles. Reported comments of users include the following: "CBD boasts considerable anti-inflammatory qualities. CBD also protects nerve cells from further damage from the shingles virus, and from future attacks. CBD will not cure shingles but can help with pain" posted by Elle Hayes on November 14, 2017; "Without a doubt CBD oil is

*https://www.quora.com/Does-CBD-help-with-shingles the only thing that actually helped and shortened the life span of my shingles outbreak" posted by Cat Lennon on February 18, 2019; "CBD can help relieve the symptoms of pain caused by shingles as well as reduce inflammation and protect nerve cells" posted by Jules S. on September 26, 2018; "CBD may help" posted by Katy Did, on December 27, 2017; "Quality CBD capsules or oil can provide effective relief for shingles. It can help with the nerve pain and inflammation. A quality CBD balm can also help with skin pain” posted by Mark Mallen, on January 30, 2018; "CBD has shown in studies that it may be able to help reduce your sensitivity to pain. Putting a CBD hemp oil topical on your shingles may be able to help decrease the inflammation which is another way that CBD can help with the pain" posted by Selim Reza on December 28, 2018.

The alleged benefits of CBD for the treatment of viral infections were most often explained by its well-known anti-inflammatory and analgesic effects rather than a direct antiviral activity. Particularly in Ebola, the alleged benefits of CBD were backed by its pharmacological 


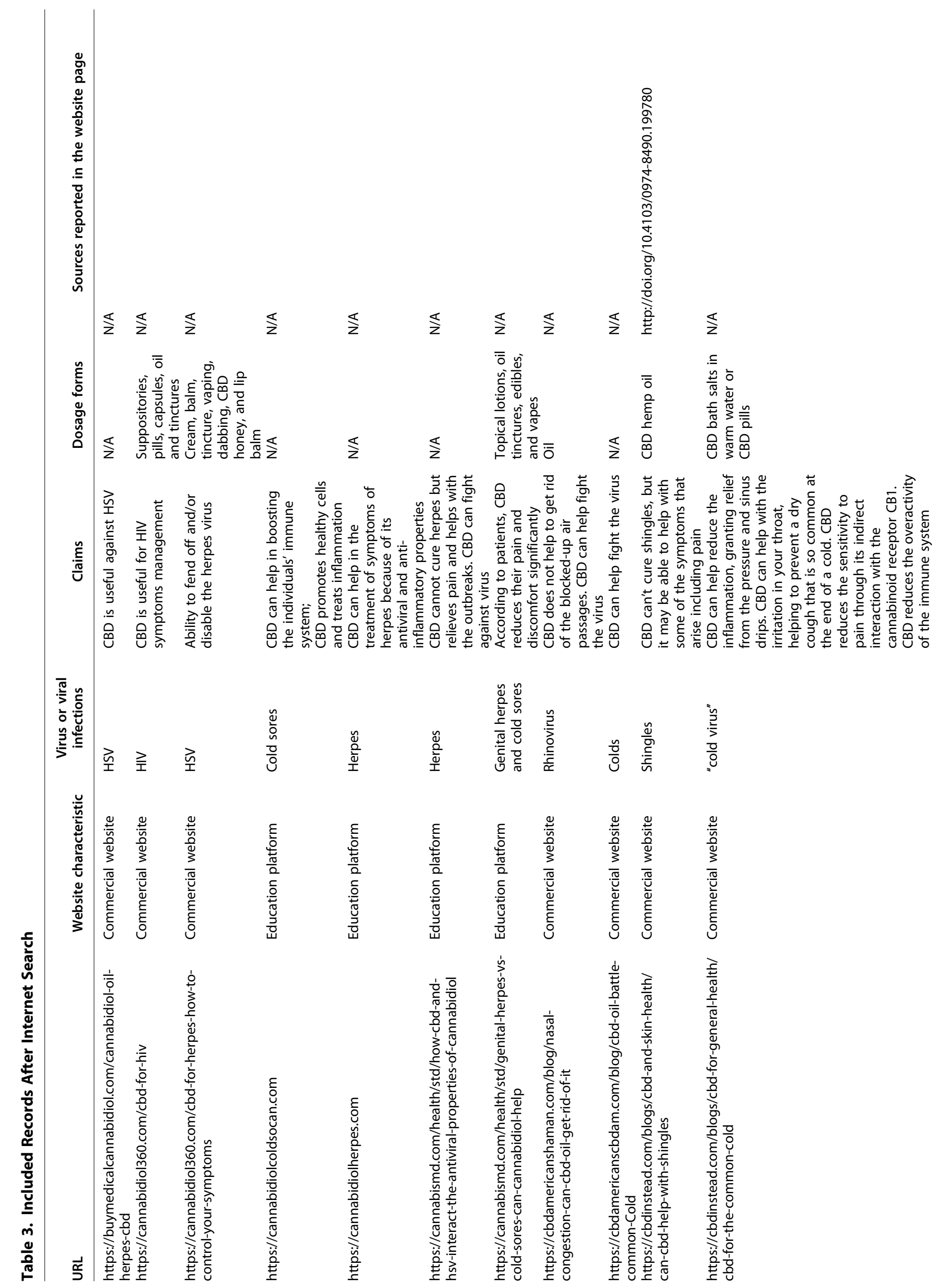




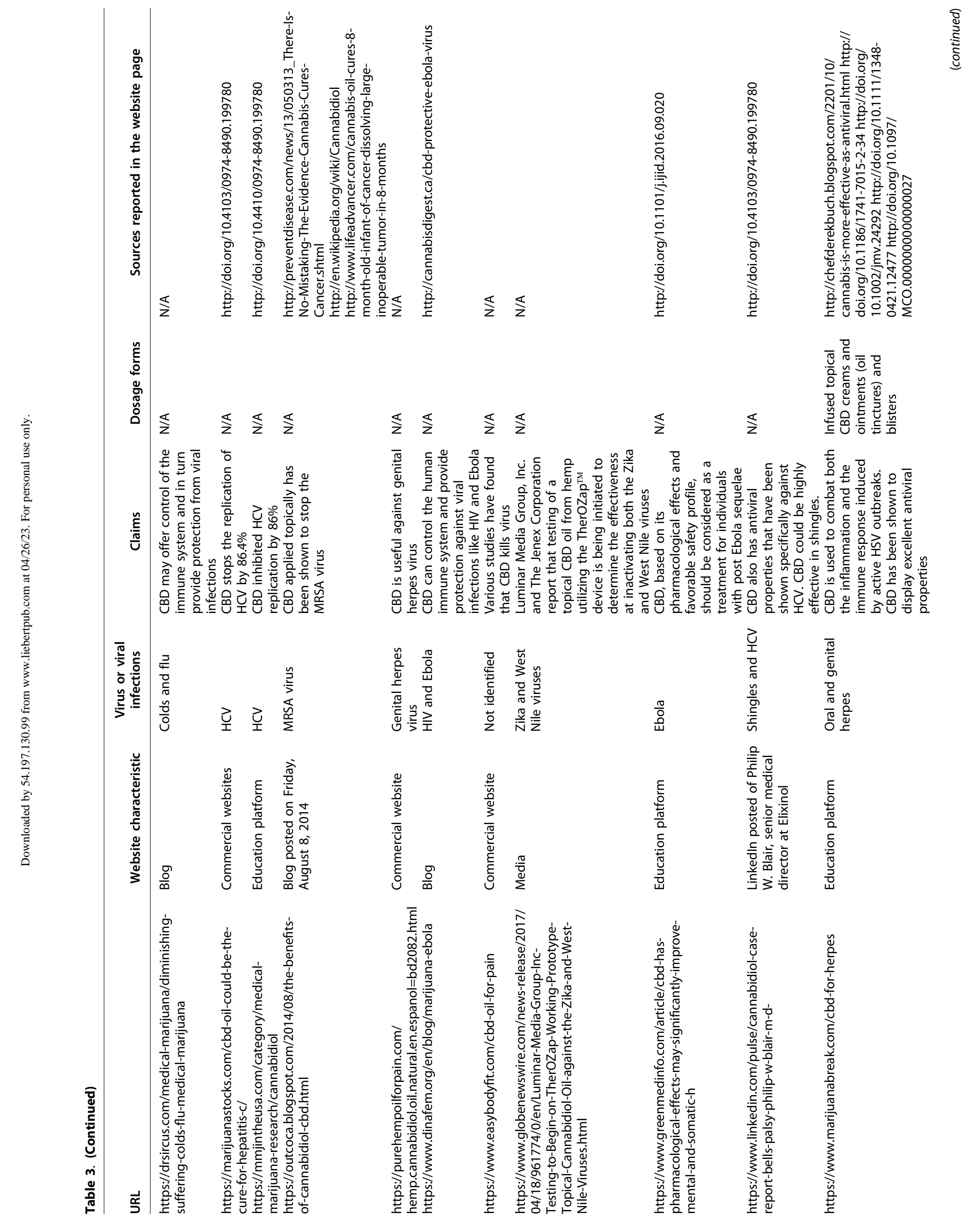




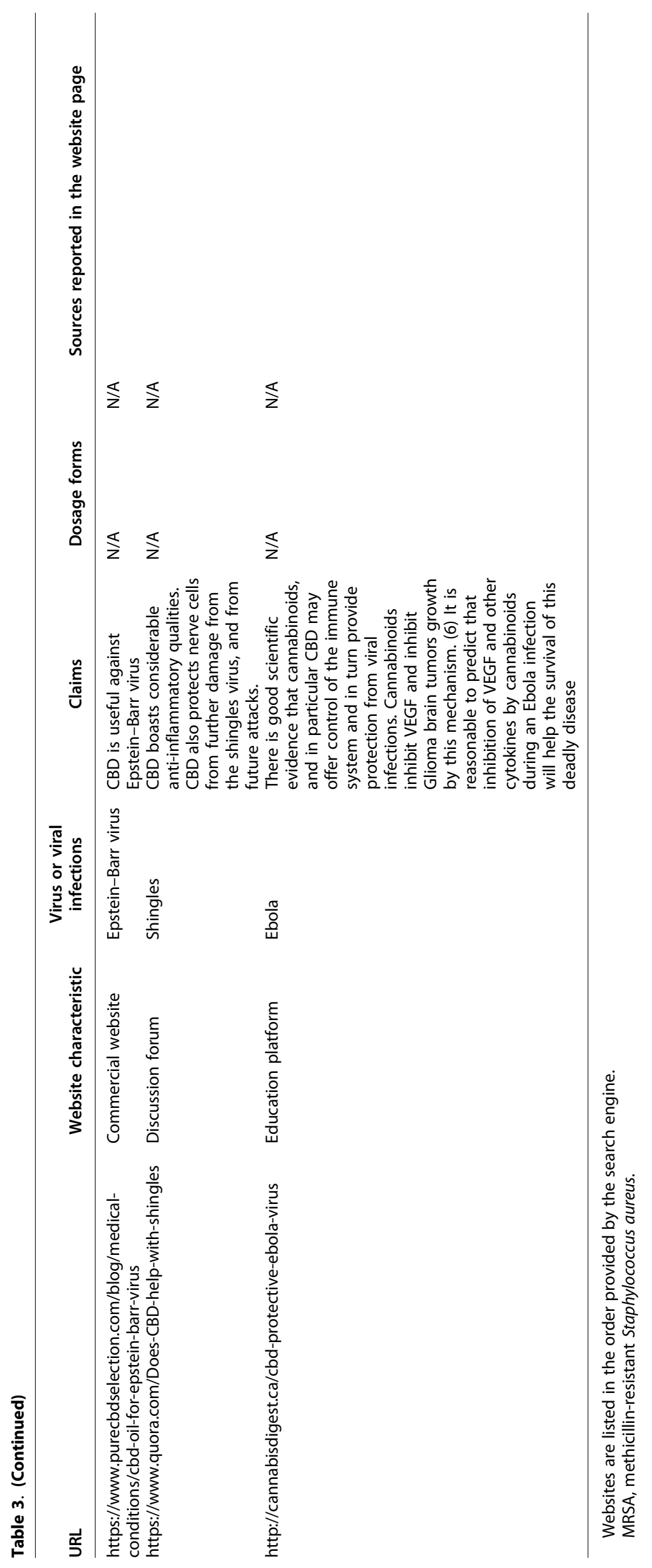


properties, which according to Reznik et al., could improve the mental and somatic health of patients suffering from post-Ebola sequelae. ${ }^{19}$

Various dosage forms of CBD have been reported, including mainly ointments, creams, and pills. Interestingly, one reference announced that a study of hempbased topical CBD oil using the TherOZap ${ }^{\mathrm{TM}}$ device was underway to determine the efficacy of CBD in inactivating Zika and West Nile viruses. ${ }^{20}$

\section{Discussion}

This systematic review sought to examine the current state of knowledge on the use of CBD in viral diseases. We first searched for scientific literature and found very little references to the antiviral effects of CBD. Then, we turned to the Internet and retrieved additional and rare instances of benefits of $\mathrm{CBD}$ in the treatment of viral infections.

PubMed search shows that currently available scientific literature provides only circumstantial evidence that CBD has a direct effect on HCV replication and indirect antiviral action against KSHV infection. ${ }^{16,17}$ Together, these findings suggest that CBD may be a novel targeted candidate for the treatment of hepatitis $\mathrm{C}$ and Kaposi sarcoma. This is to be welcomed as these pathological conditions affect millions of people globally and offer limited therapeutic options to patients so far. $^{21,22}$ Importantly, the observed in vitro effects of CBD occur at concentrations achieved in humans with well-tolerated therapeutic doses of Epidiolex (up to $20 \mathrm{mg}$ per $\mathrm{kg}$ of body weight per day), ${ }^{23}$ suggesting that these findings might be easily translated into clinics. However, there is evidence that, other cannabinoids such as $\Delta^{9}$-THC may instead enhance infection and replication of KSHV and promote KSHV-induced endothelial transformation. ${ }^{24}$

In addition to its antiviral activity on HCV and KSHV, $\mathrm{CBD}$ was found to reverse the deleterious effects of neuroinflammation in TMEV-infected mice. ${ }^{18}$ Indeed, following intracranial inoculation of TMEV, susceptible mouse strains developed a chronic demyelinating disease similar to MS. ${ }^{25}$ This study actually does not provide any evidence for a direct antiviral effect of $\mathrm{CBD}$, nonetheless it suggests the ability of CBD to affect the neuroinflammatory events underlying the pathogenesis of MS. Although MS cannot by any means be considered a viral disease, several lines of evidence suggest the contribution of some human viruses in its etiology and pathogenesis. ${ }^{26}$ Cannabinoids, including CBD, are currently used to treat symptoms of pain and spasticity in $\mathrm{MS},{ }^{27}$ and recently, they are gaining increasing interest for their immunomodulating properties that might affect the immunoinflammatory mechanisms underlying MS pathogenesis and progression. ${ }^{28}$ Available evidence thus strongly warrants preclinical and clinical studies aimed at establishing the potential of CBD as an immunomodulating agent in MS, considering its effects on the immune system and on other factors contributing to MS, possibly including viral infections.

Searching the Internet for claims about conventional as well as alternative therapeutics is nowadays of paramount importance, in view of the extensive and continuously increasing use of the Internet by common people to retrieve health-related information. ${ }^{14}$ Our DDG search on the Internet found more indications for CBD, including in the treatment of oral and genital herpes, HIV/AIDS, cold and flu, shingles, hepatitis C, Ebola, mononucleosis, progressive multifocal leukoencephalopathy, and West Nile and Zika fevers. Reportedly, the antiviral potential of CBD lies in the fact that it may affect both the innate and adaptive immune cells functions ${ }^{29,30}$ and host inflammatory responses play a critical role in the pathogenesis of these viral diseases. However, apart from hepatitis C, there is a very real lack of scientific evidence supporting the other alleged antiviral properties of CBD.

Claims about the benefits of using CBD in viral infections were largely reported by CBD online retailers and most often appear to be a biased interpretation of the scientific literature or a dishonest manipulation of the information for commercial purposes. For instances, the purported benefits of CBD use in hepatitis $C$ appear to be extrapolated from a single in vitro study in which CBD showed to inhibit HCV replication. ${ }^{16}$ Overall, this situation comes to be problematic when desperate patients, because of the limited therapeutic options they have for their condition, are embracing very enthusiastically these claims. Indeed, misleading claim raises significant public health concerns, as it may keep some patients from accessing appropriate, well-established antiviral therapies or looking out for possible risks associated with CBD use. ${ }^{31}$ In addition, since CBD-based products are generally easier to obtain over the counter by the general public, physicians may be confronted with the effects of CBD-and thus the possibility of unwanted interactions with standard therapies-even when they do not prescribe it themselves.

On the other side, however, claims about the use of CBD in oral and genital herpes, shingles, and Ebola are plausible on the basis of the anti-inflammatory and 
analgesic properties of $\mathrm{CBD}^{32}$ and therefore deserve proper attention by the scientific community. For instance, in Ebola, CBD has been proposed to improve the mental and somatic health of patients suffering from post-Ebola sequelae. ${ }^{19}$ In addition, ameliorating inflammation, which is common in these conditions, ${ }^{33-35}$ could be beneficial for patients. Likewise, the anecdotal claims retrieved in an online forum concerning the symptomatic benefits of CBD in shinglesassociated inflammation and pain, despite being based just on the personal experience of one subject, suggest the opportunity to consider testing CBD in clinical trials as an add-on therapeutic for shinglesrelated distress.

Although preliminary results achieved so far are encouraging, much remains to be done before $\mathrm{CBD}$ reaches the marketplace as a treatment for viral diseases. Currently, there is no evidence from properly designed clinical trials to support the use of CBD for the treatment of hepatitis C and Kaposi sarcoma. Only well-powered double-blind randomized, controlled clinical trials on the efficacy of pure CBD are useful to recommend $\mathrm{CBD}$ as a help for patients with viral infections. In addition, current evidence supporting the use of CBD in virally induced pathological conditions is confined to only two in vitro and one in vivo studies, which overall are poorly predictive of definitive outcomes in humans. Therefore, additional studies are needed to validate or consolidate current preclinical evidence, and to assess the efficacy of CBD in patients with the aforementioned viral diseases.

Procuring CBD even for research purpose still remains a daunting task in some parts of the globe, due to restrictive national regulations. ${ }^{36}$ Although World Health Organization has recently withdrawn CBD from the international drug control treaties, many regulatory authorities such as FDA have denied to update their restrictive position. ${ }^{37}$ Another concern with $\mathrm{CBD}$ research is that CBD-based products purchased online or in shops have not been subject to the same level of regulatory scrutiny before reaching the marketplace as conventional therapies. Therefore, their purity, quality, and dosage may be unreliable. ${ }^{38}$

In conclusion, the plausibility of $\mathrm{CBD}$ use for $\mathrm{HCV}$ and $\mathrm{KSHV}$ is there, but the current state of evidence is limited and only supports consolidating existing preclinical evidence through additional studies or doing clinical trials, not recommending its use. Claims about the other apparent antiviral effects of CBD abound and should push us to investigate the real ben- efit of CBD to overcome biases inherent in anecdotal evidence. In particular, putative usefulness of CBD in the post-Ebola syndrome ${ }^{19}$ or for shingles-associated inflammation and pain is plausible considering the established pharmacology of CBD but needs proper assessment in well-designed clinical trials. Meanwhile, CBD sellers should stop promoting claims that are not backed by scientific evidence. Misleading claims represent both a threat to public health and a violation of consumer access to accurate information. Large international collaboration is needed to regulate online shopping and enable consumers to make an informed purchase.

\section{Authors' Contributions}

Conception and design of the study: F.M., M.C., A.M.T., B.P., and M.S. Acquisition of data: A.M.T. and M.C. Analysis and interpretation of data: A.M.T, M.C., and F.M. All authors were involved in drafting the article or revising it critically for important intellectual content, and all authors approved the final version to be published. All authors agree to be accountable for all aspects of the work in ensuring that questions related to the accuracy or integrity of any part of the work are appropriately investigated and resolved and declare to have confidence in the integrity of the contributions of their co-authors.

\section{Author Disclosure Statement}

The authors declare there are no conflicts of interest.

\section{Funding Information}

A.M.T. was supported by a postdoctoral fellowship from the University of Insubria to study the pharmacology of plant extracts.

\section{Supplementary Material}

Supplementary Table S1

Supplementary Table S2

\section{References}

1. Abrams DI. The therapeutic effects of Cannabis and cannabinoids: an update from the National Academies of Sciences, Engineering and Medicine report. Eur J Intern Med. 2018:49:7-11.

2. Klein TW. Cannabinoid-based drugs as anti-inflammatory therapeutics. Nat Rev Immunol. 2005;5:400-411.

3. Reiss CS. Cannabinoids and viral infections. Pharmaceuticals. 2010;3: 1873-1886.

4. Tahamtan A, Tavakoli-Yaraki M, Rygiel TP, et al. Effects of cannabinoids and their receptors on viral infections. J Med Virol. 2016;88:1-12.

5. Babalonis S, Haney M, Malcolm RJ, et al. Oral cannabidiol does not produce a signal for abuse liability in frequent marijuana smokers. Drug Alcohol Depend. 2017;172:9-13. 
6. Pisanti S, Malfitano AM, Ciaglia E, et al. Cannabidiol: state of the art and new challenges for therapeutic applications. Pharmacol Ther. 2017;175: 133-150.

7. Sekar K, Pack A. Epidiolex as adjunct therapy for treatment of refractory epilepsy: a comprehensive review with a focus on adverse effects. F1000Res. 2019;8:pii: F1000 Faculty Rev-234.

8. Kapoor R, Sharma B, Kanwar SS. Antiviral phytochemicals: an overview. Biochem Physiol Open Access. 2017;6:1-7.

9. Naithani R, Mehta RG, Shukla D, et al. Antiviral activity of phytochemicals: a current perspective. In: Watson R, Zibadi S, Preedy V, eds. Dietary components and immune function. Humana Press: Totowa, NJ, 2010, pp. 421-468.

10. Cowan MM. Plant products as antimicrobial agents. Clin Microbiol Rev. 1999;12:564-582.

11. Śledziński $P$, Zeyland J, Słomski R, et al. The current state and future perspectives of cannabinoids in cancer biology. Cancer Med. 2018;7:765-775.

12. Orzalli MH, Kagan JC. Apoptosis and necroptosis as host defense strategies to prevent viral infection. Trends Cell Biol. 2017;27:800-809.

13. Corroon J, Phillips JA. A cross-sectional study of cannabidiol users. Cannabis Cannabinoid Res. 2018;3:152-161.

14. Lombardo $S$, Cosentino M. Internet use for searching information on medicines and disease: a community pharmacy-based survey among adult pharmacy customers. Interact J Med Res. 2016;5:e22.

15. Briscoe $\mathrm{S}$. Web searching for systematic reviews: a case study of reporting standards in the UK Health Technology Assessment programme. BMC Res Notes. 2015;8:153.

16. Lowe HIC, Toyang NJ, McLaughlin W. Potential of cannabidiol for the treatment of viral hepatitis. Pharmacognosy Res. 2017;9:116-118.

17. Maor Y, Yu J, Kuzontkoski PM, et al. Cannabidiol inhibits growth and induces programmed cell death in kaposi sarcoma-associated herpesvirusinfected endothelium. Genes Cancer. 2012;3:512-520.

18. Mecha M, Feliú A, Iñigo PM, et al. Cannabidiol provides long-lasting protection against the deleterious effects of inflammation in a viral model of multiple sclerosis: a role for A2A receptors. Neurobiol Dis. 2013;59: 141-150.

19. Reznik SE, Gardner EL, Ashby CRJ. Cannabidiol: a potential treatment for post Ebola syndrome? Int J Infect Dis. 2016;52:74-76.

20. Luminar Media Group. Testing to begin on TherOZap ${ }^{\mathrm{TM}}$ working prototype \& topical cannabidiol oil against the Zika and West Nile viruses. 2017. Available at https://www.globenewswire.com/news-release/2017/04/18/ 961774/0/en/Luminar-Media-Group-Inc-Testing-to-Begin-on-TherOZapWorking-Prototype-Topical-Cannabidiol-Oil-against-the-Zika-and-WestNile-Viruses.html (last accessed December 16, 2019).

21. Lebbe C, Garbe C, Stratigos AJ, et al. Diagnosis and treatment of Kaposi's sarcoma: European consensus-based interdisciplinary guideline (EDF/ EADO/EORTC). Eur J Cancer. 2019;114:117-127.

22. Zajac M, Muszalska I, Sobczak A, et al. Hepatitis C-New drugs and treatment prospects. Eur J Med Chem. 2019;165:225-249.

23. Devinsky O, Cross JH, Wright S. Trial of cannabidiol for drug-resistant seizures in the Dravet syndrome. N Engl J Med. 2017;376:2011-2020.

24. Zhang X, Jian FW, Kunos G, et al. Cannabinoid modulation of Kaposi's sarcoma-associated herpesvirus infection and transformation. Cancer Res. 2007;67:7230-7237.

25. Clatch RJ, Melvold RW, Dal Canto MC, et al. The Theiler's murine encephalomyelitis virus (TMEV) model for multiple sclerosis shows a strong influence of the murine equivalents of HLA-A, B, and C. J Neuroimmunol. 1987;15:121-135.

26. Lycke J. Trials of antivirals in the treatment of multiple sclerosis. Acta Neurol. Scand. 2017;136:45-48.

27. Nielsen S, Germanos R, Weier M, et al. The use of cannabis and cannabinoids in treating symptoms of multiple sclerosis: a systematic review of reviews. Curr Neurol Neurosci Rep. 2018;18:8.

28. Zhou T, Ahmad TK, Alrushaid S, et al. Therapeutic impact of orally administered cannabinoid oil extracts in an experimental autoimmune encephalomyelitis animal model of multiple sclerosis. Biochem Biophys Res Commun 2019;516:373-380.
29. Mabou Tagne A, Marino F, Legnaro M, et al. A novel standardized Cannabis sativa $\mathrm{L}$. extract and its constituent cannabidiol inhibit human polymorphonuclear leukocyte functions. Int J Mol Sci. 2019;20:1833.

30. Burstein S. Cannabidiol (CBD) and its analogs: a review of their effects on inflammation. Bioorganic Med Chem. 2015;23:1377-1385.

31. Ernst E. How the public is being misled about complementary/alternative medicine. J R Soc Med. 2008;101:528-530.

32. Hammell DC, Zhang LP, Ma F, et al. Transdermal cannabidiol reduces inflammation and pain-related behaviours in a rat model of arthritis. Eur J Pain (United Kingdom). 2016;20:936-948.

33. Carr DJJ, Tomanek L. Herpes simplex virus and the chemokines that mediate the inflammation. Curr Top Microbiol Immunol. 2006;303:47-65.

34. Wang JP, Kurt-Jones EA, Shin OS, et al. Varicella-Zoster virus activates inflammatory cytokines in human monocytes and macrophages via Tolllike receptor 2. J Virol. 2005;79:12658.

35. Baize S, Leroy EM, Georges AJ, et al. Inflammatory responses in Ebola virus-infected patients. Clin Exp Immunol. 2002;128:163.

36. Corroon J, Kight R. Regulatory status of cannabidiol in the United States: a perspective. Cannabis Cannabinoid Res. 2018;3:190-194.

37. World Health Organization. CANNABIDIOL (CBD) Critical Review Report. In: Expert Committee on Drug Dependence Fortieth Meeting, Geneva, June 4-7, 2018.

38. Bonn-Miller MO, Loflin MJE, Thomas BF, et al. Labeling accuracy of cannabidiol extracts sold online. JAMA. 2017;318:1708-1709.

Cite this article as: Mabou Tagne $A$, Pacchetti $B$, Sodergren $M$, Cosentino M, Marino F (2020) Cannabidiol for viral diseases: hype or hope?, Cannabis and Cannabinoid Research 5:2, 121-131, DOI: 10.1089/can.2019.0060.

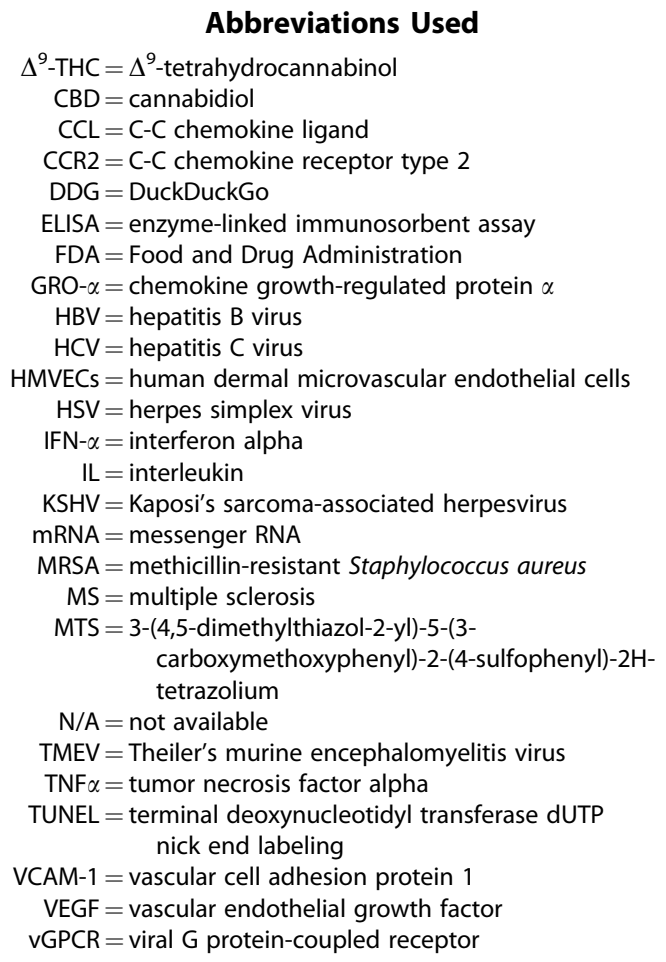

